\title{
Recolocar-se na Memória, Reinscrever-se na Temporalidade: identificação de si enquanto negra como eventualidade
}

\author{
Tainara Lúcia Pinheiro ${ }^{a}$ \\ Carmem Izabel Rodrigues ${ }^{b}$
}

Resumo: Ser negra enquanto afirmação política de um corpo não é algo inato para quem vive a experiência de ser vista como tal, mas parte de um processo de identificação revestido de intencionalidade que objetiva uma existência não subordinada. Nosso objetivo nesse artigo é compreender de que forma a tipificação de si enquanto negra, a partir do evento de se atribuir esta identificação, instaura uma nova temporalidade na experiência vivida de mulheres negras, implicando em diferentes formas de tipificar o mundo da vida nas temporalidades anterior e posterior ao evento. Recorremos à metodologia etnográfica de abordagem fenomenológica para alcançar as estruturas presentes na consciência das mulheres negras interlocutoras desta pesquisa, uma vez que consciência compreende aspectos sensoriais e não sensoriais, como emoção, pensamento e memória.

Palavras-chave: Identificação, Relações Raciais, Memória, Temporalidade, Evento.

"Eu era negra, não é? Eu sempre fui negra, só me foi negada essa possibilidade de identificação". A fala aspeada anteriormente foi dita por uma interlocutora durante entrevista para realização da pesquisa

a Mestre em Sociologia e Antropologia (PPGSA-UFPA). Email: tainaraluc@ hotmail.com.

b Professora do Programa de Pós-graduação em Sociologia e Antropologia (UFPA). Email: cizbel@gmail.com. 
etnográfica de abordagem fenomenológica aqui apresentada, voltada para processos de identificação construídos por essas mulheres a partir da experiência do racismo presente em seu cotidiano vivido na cidade. Uma das questões levantadas nas entrevistas realizadas com 10 mulheres militantes pelo movimento negro e feminista em Belém-PA foi se essas mulheres sempre se declararam negras. Todas as mulheres entrevistadas responderam que não. Antes de passarem a se identificar como negras, elas se identificavam, em relação à raça/cor, como 'morenas', 'pardas' ou 'brancas'1'; esta última denominação aparecia quando usavam de artifícios como alisar os cabelos ou maquiar o rosto com objetivo de 'afinar' os traços.

Acompanhando esses posicionamentos identificativos estavam noções de diferenciação na tipificação das coisas do mundo da vida no antes e no depois do momento em que passavam a se identificarem como mulheres negras; em geral, no antes, a negritude era vista como algo ruim, sujo, pejorativo em vários aspectos, algo do que deveriam se afastar, algo que as tornava, de algum modo, menos humanas, menos gente. Esse dado, a desumanização, pode ser interpretado a partir da discussão feita por Grada Kilomba (2019) quando a autora define os três níveis que compõem a esfera subjetiva do sujeito: político, social e individual; quando reconhecida nesses três diferentes níveis, a pessoa pode se considerar sujeita, ou seja, indivíduo relacional em sua sociedade. Ser sujeito é estar intersubjetivamente em uma sociedade, partilhando, propondo e tendo seus interesses validados. Nesse sentido, é na esfera de ser parte de uma agenda que o racismo - expresso também nos estereótipos negativos relativos à população negra - impede pessoas negras de serem sujeitas.

Kilomba desenvolve sua tese afirmando que o racismo estrutural se apresenta quando pessoas negras são excluídas das estruturas políticas e sociais de uma sociedade, privilegiando sujeitos brancos; o racismo institucional, por sua vez, versa sobre o tratamento desigual dado aos diferentes grupos; no racismo cotidiano (olhares, vocabulário, representações) é negado ao outro negro (outridade do branco) o direito 
de existir como igual. $\mathrm{O}$ racismo cotidiano poderia ser sintetizado em "um padrão contínuo de abuso que se repete incessantemente ao longo da biografia de alguém" (Kilomba 2019:80). As estruturas de dominação produzem opressões e explorações reais também no espaço privado, no campo das afetividades, portanto, é impossível separá-los nas dinâmicas de sofrimento psíquico.

E é a partir das dinâmicas de sofrimento causadas pelas esferas públicas e privadas que o histórico de negativação de qualquer aproximação da identificação enquanto negro que a necessidade de distanciamento da negritude ganha força, pois "[...] o negro tomou o branco como modelo de identificação, como única possibilidade de tornar-se gente" (Souza 1983:18). Deve-se atentar, entretanto, para a questão de que, nesse processo de negação, não é com o sujeito negro que se lida, mas com o imaginário branco do que a negritude deveria ser; "são os aspectos negados do eu branco reprojetados em nós, como se fossem retratos autoritários e objetivos de nós mesmas/os" (Kilomba 2019:38), que inevitavelmente geram um trauma psíquico, uma vez que as imagens que confrontam o sujeito negro não são realistas nem gratificantes; esse trauma não permite que o indivíduo se conecte com a sociedade pensada, de maneira inconsciente, como branca ${ }^{2}$. Frente a essas questões, temos que um dos mecanismos de defesa do ego para a resolução de conflitos emocionais é a recusa, recusa em reconhecer a verdade (Kilomba 2019). Nas falas das mulheres entrevistadas, frases como: "eu achava que não era nada", "eu achava que nunca tinha sofrido racismo" são ditas repetidas vezes.

O presente artigo busca compreender de que forma a tipificação de si, enquanto negra, a partir do evento de se atribuir esta identificação, instaura uma nova temporalidade na experiência vivida de mulheres negras. Experiência eventual essa que é capaz de inaugurar uma nova relação entre a dinâmica da experiência vivida enquanto temporalidade, implicando em diferentes formas de tipificar o mundo da vida nas temporalidades anterior e posterior ao evento. É a influência do evento identificatório para as mudanças de tipificações das coisas 
do tempo que buscamos compreender, evento esse que muitas vezes acontece nos momentos de violência racista, que posicionam socialmente sujeitos que deveriam ser subalternizados.

Recorremos à abordagem fenomenológica porque nos possibilita alcançar as estruturas presentes na consciência do sujeito. Consciência compreende aspectos sensoriais e não sensoriais, como emoção, pensamento e memória. Essas memórias são imagens de eventos passados, uma maneira de acessar o que conhecemos como passado (Ismael 2010)3. Para acessar as memórias dos eventos (Dastur 2000) experienciados no mundo da vida (Schütz 2012) das mulheres entrevistadas, utilizamos o recurso de histórias de vida por meio de entrevistas gravadas e transcritas, conversações continuadas cujos temas abordados foram pensados e escolhidos por convirem à pesquisa.

Descrevendo a experiência narrada como evento que instaura o desencadeamento da percepção identificatória supracitada enquanto processo, enquanto tornar-se, é possível compreender possíveis motivos pelos quais a negritude, muitas vezes, é uma descoberta, uma ruptura de temporalidades, um evento que marca a existência e constrói outras (novas) possibilidades (Dastur 2000). Ser negra enquanto afirmação política de um corpo, então, não é algo inato para quem vive a experiência de ser vista como tal, mas um processo de identificação revestido de intencionalidade que objetiva uma existência não subordinada. Dastur (2000) argumenta que o evento é sempre uma surpresa, o inesperado que de repente acontece sem deixar antes por avisado. Tomando o Evento como conceituado anteriormente, ele instaura temporalidades na medida em que ocorre e influencia diretamente nas construções de identificações.

Aqui, nossa preocupação está direcionada à interpretação de um fenômeno específico: o racismo. No capítulo A Experiência Vivida do Negro, Fanon (2008) apresenta e discute um evento, o evento da identificação de si por meio do olhar de outro alguém que racializa, que vê e afirma "Olhe, um preto!" (Fanon 2008:103). Quando falamos da experiência eventual vivida pelas interlocutoras desta pesquisa, trata- 
mos exatamente desse evento - a identificação de si mediante a racialização de si por um outro. Só podemos pensar esse evento quando em relação aos processos identificatórios.

\section{Identificar-se como negra}

Em fenomenologia, não existe identidade estável e objetiva separada da intencionalidade da consciência; a identidade é, portanto, uma temporalização que existe graças à intencionalidade. Em outros termos, estou agora assumindo um papel social porque me é interessante - ou imposto (Maldonato 2005). Identidade e alteridade se encontram nas estruturas de um tempo. É intersubjetivo e por isso toda identidade se constrói na relação com o outro. $\mathrm{O}$ Eu é quando se difere do Outro. E a pergunta 'o que é ser eu?' têm como resposta o relato de uma história, de uma identidade (Maldonato 2005). Responder essa pergunta é como parar num ponto da vida e contar como que, até ali, se foi sendo.

É justamente pela possibilidade de trânsito que pensamos a experiência das interlocutoras com a não identificação enquanto negras como possível. É fato que existe uma série de questões sobre tentativas de anulação de negritude e não negamos isso, pelo contrário, mas é fato também que por vezes e nos espaços diversos por onde transitaram e transitam, a negritude dessas mulheres não foi ou não precisou ser acionada para que assumissem os diversos papéis sociais que lhes pertencem. É no momento em que o debate político sobre questões relativas a gênero e raça ganha sentido para elas que elas se engajam no projeto de deixar de lado as máscaras brancas (Fanon 2008) no que tange às suas experiências vividas. As máscaras só podem ser deixadas de lado quando ser negra se apresenta como uma questão, quando, por algum motivo, essa identificação é racionalizada, motivo esse que geralmente - mas não somente - é apresentado de maneira violenta. Rose ${ }^{4}$, que viajou em turnê como dançarina, nos conta que:

Foi muito cruel esse processo [de descoberta de negritude], principalmente na Espanha e em Portugal [...] Essa viagem em especial 
foi muito complicada, foram três meses de turnê e ao final eu já estava bastante conturbada mesmo. Foi muito cruel o processo de se perceber enquanto negra a partir desse olhar, sabe, pejorativo, diminuidor, racista, do outro, objetificante. E aí eu voltei de lá bastante 'crisada' com isso sim e bastante desnorteada também sobre o que eu ia fazer com essa descoberta. Eu era uma mulher negra que não sabia disso e me foi mostrado dessa maneira bastante cruel. Tu não te visualizas, não te enxergas, mas eles sabem que tu és negra. E aí? O que eu vou fazer disso? (Entrevista com Rose, 2016).

Para Fanon (2008), a pessoa negra, obrigada a responder a dois sistemas de referência, é ensinada que os seus costumes estão em contradição com a civilização - é no encontro com o outro, branco, que a inferioridade do negro é revelada, imposta de forma escancarada; esse outro que reconhece a pessoa negra como alguém que existe em triplo: em si, na raça e em sua ancestralidade, esse outro que aprisiona e torna turvas as possibilidades de escolha, que aponta um só caminho: a brancura.

A pessoa negra que racionaliza o mundo e é excluída desse mesmo mundo em nome do preconceito de cor é obrigada a lidar com aquilo que é irracional e "para um homem que só tem como arma a razão, não há nada de mais neurotizante do que o contato com o irracional" (Fanon 2008:110). Muitas acreditam e por muito tempo, afetadas por diversas opressões que vêm de todos os lados e sem saber o motivo, que só resta lançar-se à irracionalidade, ao jogo imputado pelo branco que se prova mais irracional do que pretende que seja o negro. Assumem as máscaras. Salinda, contando da sua experiência, relata:

Como a minha mãe era ligada ao movimento negro, eu tive essa construção [de negritude] desde criança. Quer dizer: eu sabia que eu era negra. Mas eu não sabia o peso que isso tinha e eu só fui descobrir isso quando eu fui para a escola e começou todos os babados, que era a galera me zoando por causa do meu cabelo, me zoando por causa da minha cor [...] Eu lembro que tinha uma menina que sempre fazia umas piadas bem escrotas comigo e com outro amigo meu, que ele era negro, ela falava que era para a gente pegar a comida pra ela: "negro, cadê minha marmita?". Essas coisas 
bem absurdas. Ela falava que eu ia ser empregada e essas coisas, então foi só quando eu... saí da minha casa que eu tive contato com o que é ser negra. Aí nisso, apesar de toda a construção que eu tive por parte da minha mãe, eu comecei a querer rejeitar essa identidade, aí eu achava que eu era parda, eu achava... Eu não queria ser negra. (Entrevista com Salinda, 2016).

Quando Salinda afirma que não queria ser negra, ela diz muito mais que isso. $\mathrm{O}$ que a frase no contexto aponta é que, de fato, o que ela não queria é sofrer racismo e para isso usa um artifício: nega a identificação. Nessa fala fica nítida a necessidade de atuação política firme para subversão de lógicas violentas.

Nilma Gomes (2017) afirma que o movimento negro brasileiro, ao assumir a responsabilidade de construir a noção de raça como potência emancipatória e fazer dessa noção seu ponto de organização e ação, educa a sociedade na medida em que reescreve a história. Olhar para a história dando a ela outra atenção é ponto fundamental na politização da raça, desse construto social fruto do racismo. Um dos principais pontos dessa politização é a responsabilização, por parte de pessoas violentadas, de quem deve ser responsabilizado pelas violências racistas. Em outros termos, apontar os responsáveis pela dívida colonial e, assim, tirar de si o peso das dificuldades que foram impostas para si graças às reminiscências do potentado colonial (Mbembe 2018a). Como resultado desse movimento educador no movimento negro, temos relatos potentes, como o de Luamanda:

A primeira vez que eu ouvi falar de mulheres negras em uma mesa foi no encontro que ia ter de mulheres estudantes e aqui tinha um coletivo que era da marcha mundial de mulheres, na época, que era das meninas do direito. Eu fui participar, eu vi uma chamada em um panfleto e fui lá no IFPA [Instituto Federal do Pará] e estava a Nazaré Cruz, então foi a primeira vez que eu vi uma mulher [negra] falar. Nossa, a Nazaré veio trazer contexto histórico das mulheres negras no Brasil, sabe? Aí, aquele dia foi um estalo, pra mim, foi muito importante ouvir a Nazaré Cruz, que até hoje tenho contato. De me ver, de ver uma mulher preta falando de como as mulheres chegaram, de como as negras africanas chegaram no Brasil, como foram escravizadas. Falou de estupro dessas 
mulheres, o que é ser mãe. Eu nunca me esqueço da Nazaré falando que ela, enquanto mulher negra grávida, na época ela já tinha tido um filho, e ela falando que o médico mal tocava nela, na barriga, um tratamento diferenciado, ai aquilo foi um despertar. Hoje, a partir da leitura e de também escrever e falar sobre violência obstétrica, eu trago a fala dela de 2008 pra agora, do que eu tô escrevendo. Ela veio trazendo um contexto histórico que, até então, eu nunca tinha despertado, parado pra ler e pra ouvir o que uma outra mulher negra tava falando, foi um dia muito especial para mim. De despertar, de me afirmar. Eu sempre soube, mas, de dizer "eu sou uma mulher negra também", de sensibilizar, de ter empatia pela dor que estava falando da experiência dela, sabe? Enquanto mulher negra grávida no posto de saúde contando a história dela, que tá trazendo também as dores históricas das mulheres, foi muito importante ouvir. Foi importante para despertar de que eu também tô nesse processo, ali foi o ponto de partida, posso dar certeza. (Entrevista com Luamanda, 2019).

Nesse sentido, tomando o relato como exemplo, temos que as máscaras brancas apontadas por Fanon (2008) são retiradas, destruídas, jogadas no lixo uma a uma no decorrer do processo de construção e afirmação de uma identidade negra positivada, e o movimento negro tem papel fundamental nesse processo. Esse processo, o "ponto de partida” de que fala Luamanda, é como despir (descobrir) feridas há muito inculcadas no antigo ser para traçar, novas marcas, conscientemente desenhadas (riscadas) em uma nova pele - negra - recém tecida na experiência de produzir, nessa relação de alteridade, uma nova identidade. Segundo Mauro Maldonado (2005) a identidade é também uma 'história de vida', não apenas autobiografia, mas

“[...] uma identidade que é, ela própria, biografia. Isto significa que a identidade assim entendida não só não é substancial, monolítica, solitária, mas é fundamentalmente plural. Poderia ser definida como uma identidade relacional, que só se dá no encontro com o outro: o outro que olha, que narra e que pode explicitar minha identidade, restituindo-a a mim como forma de uma história de vida narrada" (Maldonato 2005:480).

Destacando o preceito lockeano de que "a autoconsciência é o que define a pessoa, porque a consciência é consciência de si, ou seja, a 
consciência reflexiva imediata de termos consciência de sermos aquela pessoa" (Maldonato 2005:484), o autor contra-argumenta que:

"Ainda que com ênfases diferentes [...] a psicanálise mostrou de que modo a identidade deriva de um processo de múltiplas identificações, de uma constante 'negociação' das contradições e dos conflitos determinados por essas mesmas identificações. A própria existência do inconsciente, da pluralidade das pessoas psíquicas (o id, o ego, o superego etc.) que o habitam - cada uma das quais perseguindo o próprio objetivo - demonstra a inanidade de qualquer representação unitária, compacta e coerente da identidade" (Maldonato 2005:482-483).

As construções identificatórias não podem ser dissociadas ou distanciadas dos contextos políticos e sociais em que são formadas. Fanon (2008) pauta seu pensamento nas interpretações da população negra no que ele chama de mundo dos brancos, na realidade violenta do mundo colonial e pós-colonial. Nesse sentido, Achille Mbembe (2018b) ultrapassa a ideia foucaultiana de biopoder para compreensão dos procedimentos de eliminação de quem é considerado inimigo - o objetivo primeiro para manutenção da segurança de si mesmo, para cunhar o conceito de necropoder, um tipo de agir pautado na política de produção de morte sedimentado em um poder não apenas soberano, mas geopolítico, colonial, que tenta manter os colonizados nos lugares projetados para eles. Necropolítica seria, então, "a submissão da vida ao poder da morte" (Noguera 2018:70).

"A expressão máxima da soberania é a produção de normas gerais por um corpo (povo) composto por mulheres e homens livres e iguais. Esses homens e mulheres são considerados sujeitos completos, capazes de autoconhecimento, autoconsciência e autorepresentação" (Mbembe 2018:9b); política, então, seria autonomia e realização de acordo coletivo comunicado e reconhecido pelo conjunto de acordantes. No romance da soberania o sujeito define e controla seu próprio significado, mas, que sujeito é esse? Sujeito completo, consciente, representativo, quem é? Sujeito que não está na mira da bala, que cabe na história, que deseja, quem é? O que se entende por 
soberania é dominado por um corpo branco. $O$ direito soberano de matar é branco.

Mbembe nos diz que uma das primeiras manifestações da biopolítica foi a escravidão colonial, uma vez que a colônia é a representação de um "lugar em que a soberania consiste fundamentalmente no exercício de um poder à margem da lei (ab legibus solutes) e no qual a 'paz' tende a assumir o rosto de uma 'guerra sem fim'" (Mbempe 2018:33b). Como resultado das ocupações coloniais, hierarquias sociais e fronteiras territoriais foram afirmadas e sustentadas, recursos foram extraídos, pessoas foram classificadas e uma gama de imaginários sociais foram construídos, imaginários que ainda hoje sustentam o exercício da soberania, da ocupação, do poder de colocar o ser colonizado no entremeio de ser sujeito ou objeto.

$\mathrm{O}$ terror esteve presente tanto na escravidão quanto em regimes coloniais contemporâneos, sendo morte e liberdade noções que caminham juntas na experiência de 'viver na dor', em um tipo de loucura. Mbembe entende que:

"Em tais circunstâncias, o rigor da vida e as provações (julgamento por morte) são marcados pelo excesso. O que liga o terror, a morte e a liberdade é uma noção 'extática' da temporalidade e da política. O futuro, aqui, pode ser autenticamente antecipado, mas não no presente. $O$ presente em si é apenas um momento de visão - visão da liberdade que ainda não chegou" (Mbembe 2018:69a).

Impossível, então, não relacionar a maneira como se vive o tempo e como se tipificam as coisas do tempo com o potentado colonial, a necropolítica e o necropoder que a sustenta. Na experiência vivida de pessoas negras, essas relações são intrínsecas e absolutamente interseccionadas.

\section{Tipificando as coisas do tempo: a experiência vivida na memória}

Entre as diversas possibilidades interpretativas abertas pelas Ciências Sociais para entender o mundo em que vivemos, recorremos, para expressar estes modelos, ao conceito de tipicalidade. Alfred Schütz 
(2012) nos diz que se trata de uma estrutura composta de um conjunto de tipificações. Tipificar é classificar em tipos as coisas da vida cotidiana, esses tipos são nomeados com a finalidade de torná-los próximos a nós, ao que já existe como experiência. A partir de um conjunto de tipificações é que construímos as referências que nos possibilitam interpretar o mundo.

A tipicalidade é formada pela dinâmica da vida na qual acumulamos experiências e, dentre estas, aquelas mais significativas para a cotidianidade sedimentam-se como estoque de conhecimento que, por sua vez, também pode ser alterado a partir de experiências que vêm ao nosso encontro no mundo. Uma ou outra tipicalidade (aquilo que é importante para a vida na igreja ou nos negócios) ganha mais relevância significativa em relação às outras que estão à mão, dependendo do momento da ação. A isso o autor chamou 'província de significado'. Dessa forma, quando falamos do evento em questão, interpretamos sua influência em um aspecto do mundo da vida destas mulheres no que se refere à construção de uma outra tipicalidade para um tipo de experiência.

Estas tipicalidades constituem temporalidades. Quando se está imerso em corrente de consciência, as experiências não são diferenciadas de forma nítida. Não há como distinguir o agora do antes, "exceto porque sei que o que acaba de passar é diferente do que passa agora" (Schütz 2012:61). A consciência da experiência na corrente de duração pura é transformada, a cada momento, em lembrança do que acaba de ter sido assim; é o lembrar que suspende a experiência da corrente de duração irreversível e modifica, assim, a consciência, transformando-a em lembrança.

Cada Agora se difere do Agora anterior. Vive-se momento a momento; cada ato intencional me leva ao Agora seguinte. Cada Agora é uma fase que se une a outras fases formando um continuum. As experiências constituídas no fluxo da duração são objetos da atenção como experiências constituídas. "Somente uma experiência passada, isto é, uma experiência que é vista em retrospectiva, como já acaba- 
da, terminada, pode ser chamada de significativa" (Schütz 2012:63). Para o autor, as experiências só são delimitadas quando no passado; só é significativo quando já foi vivenciado no mundo da vida, pois "a possibilidade de recuperação pela memória é, de fato, o primeiro requisito de toda construção racional” (Schütz 2012:65).

Tomando a temporalidade como fundamento da experiência vivida, desenvolvemos uma abordagem dinâmica acerca da identificação racial adotada por interlocutoras desta pesquisa, na medida em que há o deslocamento dinâmico de tipicalidades no devir próprio da vida, especialmente um tipo de dinamismo que, com a sua ocorrência enquanto evento, abre uma nova temporalidade para quem vive essa experiência de determinado modo. Experiência vivida, que Avtar Brah (2006) entende como uma construção cultural, um processo de significação que constitui a realidade. Experiência é, para a autora, uma prática de atribuição de sentido, é o lugar onde o sujeito se forma; por isso,

"[...] como uma pessoa percebe ou concebe um evento varia segundo como 'ela' é culturalmente construída: a miríade de maneiras imprevisíveis em que tais construções podem se configurar no fluxo de sua psique; e, invariavelmente, em relação ao repertório político dos discursos culturais à sua disposição. 'Histórias' coletivas são também, é claro, culturalmente construídas no processo de atribuir significado ao cotidiano das relações sociais" (Brah 2006:362).

A noção de experiência, nesses termos, é alinhada à epistemologia feminista negra que tem como fundamento experiências coletivas e visões de mundo. Todas as mulheres entrevistadas compartilham de visões de mundo alinhadas à epistemologia feminista negra. $\mathrm{O}$ uso da experiência vivida para significação da cotidianidade não está por acaso - é a experiência vivida que possibilita a distinção entre conhecimento e sabedoria; pessoas que vivem na margem precisam ser sábias, uma vez que o conhecimento desatrelado de sabedoria não as protege, protege apenas quem detém o poder, e a sabedoria está na experiência (Collins 2019). Quando a experiência vivida é analisada, assume múl- 
tiplas significações; é nesse sentido que apresentamos as elaborações das interlocutoras sobre suas experiências vividas no tempo e na memória. Aramides relara que:

A gente começa a ver, parece que tu colocas uma lupa no mundo, então tu começas a rever algumas situações da tua vida e 'ah, então isso era racismo, isso era machismo’ então a partir disso, a partir dali eu comecei a olhar para trás mesmo e ver todas as situações, olhar que no presente... principalmente, eu ia botar uma menina negra no mundo, e o que eu ia falar pra essa menina? Eu vou fazer igual eu fui educada? Pensar que todo mundo era igual? Pensar que... pra não pensar em racismo, até porque os meus pais não tiveram essa formação, eles não tinham essa informação pra me dar, então 'não, quero dar outra formação pra minha filha! Quero dar um novo mundo pra minha filha. (Entrevista com Aramides, 2019).

Aramides projetou o futuro na medida em que pensava no passado. Esse exemplo explicita que nós somos seres temporais e o nosso tempo carrega história, registra nossa história, é o tempo da experiência. Costumamos dizer que um evento dá origem ao próximo e que isso é parte da dinâmica do tempo - experimentamos nossas histórias em etapas. A noção de continuidade fenomenológica é, em parte, extrapolação do cérebro; uma sequência de eventos distintos se confunde com uma duração única e o que preenche o retrato de uma história psicológica é a incorporação da consciência perceptiva em um fluxo que é incluído na memória e pode ser descrito por ela (Ismael 2010).

Entre as memórias representacionais, ou seja, aquelas que representam o mundo como um caminho, as memórias episódicas e as autobiográficas atuam juntas, informando sobre experiências passadas. Ao passo que a episódica condensa experiências de vida, a autobiográfica constitui o sujeito como temporal - alguém capaz de avaliar o passado (Ismael 2010). No caso das interlocutoras desta pesquisa, falas como "antes eu não via assim" constituem a tipificação na temporalidade anterior ao evento, comparado com a tipificação posterior a ele.

O fluxo dos conteúdos perceptivos está no contexto psicológico estruturado pela memória. Representações do tempo são arranjadas 
de modo a organizar experiências passadas e sempre que se lembra da experiência ela é reorganizada na memória, ou seja, a memória é reconstrutiva - é o que foi aqui e agora (Ismael 2010). E no hoje, no agora, no que acontece depois do evento, mulheres negras se constroem enquanto negras, tipificando as coisas do tempo de uma maneira diferente e inclusive a si mesmas de modo diferente, uma vez que articulam e reinventam suas memórias a partir de outros significantes. Zaíta relata que:

Do jardim 1, jardim 2 até o convênio, até o ensino médio, sempre foi escola particular [que estudei]. E não é porque a gente tinha recursos para isso, até porque nós éramos três filhos, era uma dificuldade muito grande. Minha mãe é autônoma e meu pai é professor de escola pública. Só que eles faziam muita questão desse ensino, dessa educação privada. Só que a gente sempre teve nesse meio que sempre foi muito branco e pessoas sempre tinham dinheiro para lanchar na hora do intervalo e a gente não tinha. Eu sempre me senti incomodada, angustiada, mas eu não sabia muito bem o porquê. Eu não tinha respostas pra... E não era algo que me fazia "ai meu Deus, o que é que tá acontecendo" era algo que eu naturalizava que eu achava que as relações eram assim... Não que eu tivesse sofrido racismo explícito, ou bullying, ou qualquer tipo de coisa nesse sentido, mas a partir do momento que eu tive acesso a esses debates que... Foi só quando eu entrei na graduação, é que eu fui olhar pra esse meu passado de escola particular e eu refleti sobre essas agonias do passado... E percebi que eu não me senti confortável naquele ambiente por causa da minha vivência, por causa da minha cor, por causa da situação financeira dos meus pais, eram pessoas muito... $\mathrm{O}$ meu ensino médio inteiro eu e a minha irmã, era só nós duas que ficávamos... A gente se sentia muito mais confortável em ficar dentro de sala na hora do intervalo, por exemplo, do que sair de sala, como todo mundo fazia. Eu era realmente bem antissocial na adolescência. Eu não ligava isso com o fato de ser negra, com fato de eu ser pobre, de eu estar em um lugar que não era para eu estar, digamos assim. Eu não conseguia fazer essas ligações, essas reflexões, eu não tinha esses questionamentos, apesar de sentir um incômodo e não saber identificar na época o porquê desses incômodos... eu achava que era simplesmente pelo fato de ser pobre e eu estava na escola de gente rica, era só isso. Mas aí não, quando a gente vai fazer a discussão mais tarde sobre raça a gente vai perceber que mínimos comportamentos restavam relacio- 
nados, entendeu? Tipo, você não ser chamada para fazer parte de um grupinho sabe? Eu era antissocial, mas eu sentia que tinha uma exclusão também por parte das outras pessoas... então, eu achava que aquilo "ah, não tenho dinheiro pra ir com eles..." não era a mesma vivência, sabe? A realidade de vida era muito diferente e na época eu ligava isso somente à questão de classe. Só que não era, sabe? Eram diversas exclusões. (Entrevista com Zaíta, 2019).

Zaíta, após conhecer debates sobre relações raciais por meio do movimento negro, passa a significar suas experiências de outra forma, atentando para a memória do que foi e tipificando violências como racismo, identificando padrões de violência com a história social do lugar onde se estabelece como sujeita. Achille Mbembe (2018a) afirma que a memória negra, atravessada pela memória colonial, é construída como lugar de perda e de constituição de uma dívida - a colônia é experimentada no corpo, mesmo muito tempo depois de ter 'desaparecido'. $\mathrm{Na}$ memória da colônia o mundo africano é um mundo de perda, perda essa que é resultado de um crime cujo responsável é culpado e está em dívida com aqueles que violou. A memória colonial é construída, no discurso negro, como um trabalho psíquico em que a meta final é a cura, e essa cura está em devolver ao sujeito a humanidade que lhe fora destituída no potentado colonial, esse "poder tipicamente funerário, tamanha era sua tendência a reificar a morte dos colonizados e a negar as suas vidas qualquer tipo de valor" (Mbembe 2018a:227).

Os símbolos públicos do potentado colonial como praças, estátuas, linguagem, trazem à memória dos ex-colonizados tudo aquilo que atormentou sua existência, impedindo-lhes de enxergar de maneira não turva o agora porque atravessado pelos traumas do passado, passado esse que talvez não tenha sido vivido no corpo, mas foi e é vivido na memória. Como constata Mbembe,

"a memória, tal como a lembrança ou o esquecimento, é constituída em primeira linha por um entrelaçamento de imagens psíquicas. É sob esta forma que ela surge no campo do simbólico, também no campo político ou ainda no campo da representação. Seu conteúdo são imagens de experiências primordiais e originárias situadas no passado e que não se pode, necessariamente, testemunhar. $\mathrm{O}$ impor- 
tante na memória, na lembrança ou no esquecimento, não é tanto a verdade, mas o jogo de símbolos e sua articulação, os pequenos atos falhos e os lapsos, em suma, a resistência à admissão. Enquanto complexos de representação poderosos, a memória, a lembrança e o esquecimento são, estritamente falando, atos sintomáticos. É nesse aspecto que derivam de uma operação psíquica e de uma crítica no tempo" (Mbembe 2018a:185).

As maneiras de mobilizar as memórias da colônia variam no tempo e nas circunstâncias do tempo entre pessoas negras, bem como suas representações e os usos dessas representações. Na literatura, na música, na religiosidade, é possível perceber uma fenomenologia da colônia desenvolvida por pessoas negras; em textos canônicos da literatura negra, a memória colonial tem como ponto fundamental a dissociação entre o eu e o sujeito onde, no lugar de um eu autêntico, é colocado um eu alienado (Mbembe 2018a). Considerando o processo de alienação, descobrir a negritude em momento eventual desvela um mundo de relações racistas no qual o senso compartilhado de democracia racial deixa de fazer sentido e, assim, as críticas ao cabelo crespo são possíveis de explicação e são significadas de outra maneira. Cida, relatando sua experiência, conta:

Você é a cabelo ruim, você é a que tem nariz de batata, então você acaba tendo medo de si próprio, então a gente acaba aprendendo a não se amar e a não gostar do nosso corpo. E quando a gente começa esse processo e vai desafiando tudo isso e diz "não, eu vou deixar meu cabelo natural e dane-se o que vão dizer", aí tu entra nos espaços e todo mundo te olha, né? Você sente que você acaba sendo um incômodo e logo no início isso dá muito medo, esse desafio, né? E aí você tem que ter muita firmeza pra você não acabar desistindo e voltando para essa mesma lógica. Então [é preciso] romper essa barreira do silêncio, do medo, e afirmar justamente essa positividade: a negritude. E não é fácil, porque a gente está indo justamente de encontro a esses discursos que fazem questão de dizer coisas horríveis, coisas pejorativas sobre a existência do outro, uma existência negra. (Entrevista com Cida, 2016).

Da mesma forma, a expectativa do futuro se altera em função, neste caso, de um projeto político antirracista, em que o objetivo vi- 
sado não é o embranquecimento de si, mas justiça social relativa também à raça.

Nas entrevistas realizadas e nos espaços de diálogo não gravados, muitas vezes as mulheres não falavam, em um primeiro momento, a palavra racismo para tipificar violências dirigidas aos seus fenótipos, mas usavam termos como 'violência', 'ruim', 'pra me deixar mal' e, em seguida, 'corrigiam' a si mesmas, explicitando como racismo o tema do qual falavam. Esse 'corrigir' a si mesma pode ser interpretado como um aprendizado de si para consigo, sobre como tornar o problema visível para que ele possa ser politicamente enfrentado, uma vez que "a negação fortalece o racismo no Brasil, uma vez que o indizível e não nomeável mantém invisível os mecanismos de operação do racismo" (Câmara 2017:85).

O tempo que a pessoa negra experiencia quando se identifica enquanto negra a partir do olhar do outro - violento ou não - é o tempo que Mbembe (2018a) define por desastre originário; é o reviver, por meio da memória, a dor de eventos que até então não eram tipificados como racistas, reviver em um corpo agora racializado por si e marcado na diáspora pela colonização, significado também pela memória do desastre originário que fora a colonização. Na experiência de Ayoluwa, o repensar as memórias, esse trânsito no tempo vivido fica muito nítido, explicitando a diferença de tipificação no tempo, na memória, portanto, anterior e posterior ao evento:

Quando tu tomas consciência, tu começas a lembrar das coisas e tu vê[s] que não era normal... porque a minha professora me tratava super diferente que ela tratava os outros alunos. Eu não entendia que era por isso [ser negra], eu achava que... sei lá... que era porque eu chorava às vezes, eu não queria ficar na escola e ela me tratava mal daquele jeito... E ela mesmo me falava "ah, tu é chorona, não sei o que”. Eu não entendia que era por eu ser negra talvez. Mas quando eu fui pra primeira serie e tal, aí sim, que eu lembro que eu tive, na terceira serie, um professor negro e, embora já nessa escola os alunos fossem negros, tipo, tinha muito auto-ódio, que eu percebi, hoje em dia, que eu penso, da parte das crianças, porque todo mundo falava que o professor negro era mau, tinha cara de 
mau, que ele era chato, mas ele não era nada disso, sabe?! Ele era muito legal, bem atencioso, às vezes ele era rígido, mas era difícil... e hoje eu penso que é porque ele era negro sabe? Ele não era esse monstro... (Entrevista com Ayoluwa, 2019).

Esse auto ódio do qual Ayoluwa fala está muito relacionado às representações racistas sobre negritude, o não querer ser pessoa negra, o aprender a odiar, depreciar. E a partir do momento que ela começa a entender, por meio de debates possibilitados pelo movimento negro, a importância da identificação enquanto negra, assume um projeto para si e para o futuro, significando de outro modo as memórias da infância. $\mathrm{O}$ relato de Ayoluwa é carregado de momentos de violência e dor, mas não é só isso. De alguma maneira, somos levados a colocar essas dores, que nos chocam, como centrais em narrativas, mas fazer essa leitura é perder o principal aqui posto: os processos de resistência e as rupturas possíveis a partir da análise da experiência vivida. Nenhuma história, nunca, em nenhum lugar, será só dor. Não é.

\section{Conclusão}

Nossa proposta foi compreender essa lacuna do evento, o que instaura nova temporalidade e constrói um novo mundo. Compreender a forma do evento e os significados que ele instaura para as temporalidades reciprocamente informadas possibilita interpretar como ele retrovém às causas antirracistas e dá sentido às ações deste grupo de mulheres que são diversas entre si. São mulheres negras cisgêneras, são de diferentes classes socioeconômicas, sexualidades e tantas outras especificidades configuram-nas. Todas as interlocutoras, a partir do momento eventual de identificação de si enquanto negras, passam a tipificar as coisas do tempo de maneira diferente, a nomear de modo mais específico os 'incômodos', 'violências', o 'sentir[-se] mal'.

A partir do entendimento e do processo de construção racial, essas mulheres dão às violências o nome que elas têm: racismo. E isso não diz respeito apenas ao que é nítida e incontestavelmente dirigido 
ao corpo físico, mas também no que atinge o corpo em várias nuances: a falta de oportunidades, de afeto, de sensação de pertencimento, de escuta e, portanto, de fala; do direito à subjetividade e a tantas outras coisas. As diferentes maneiras de tipificar as coisas do tempo nos permitem responder uma pergunta antiga feita ao movimento negro e no movimento negro, que é: é preciso sofrer racismo para ser negro? A resposta é: sim, é preciso sofrer racismo para ser negro porque, a partir do momento em que esse entendimento acontece, tudo na vida muda e todas as experiências guardadas na memória são revisitadas e ressignificadas, experiências de dor, de violência, memórias que muitas vezes essas pessoas queriam que nunca tivessem existido, memórias que queriam que fossem esquecidas.

A partir do evento, a relação dessas mulheres com o tempo é outra. Talvez nem com o tempo, primordialmente, mas com a memória. A experiência de racismo cotidiano é atemporal (Kilomba 2019), mas as reincidências do passado e as não possibilidades de futuro fazem com que essa experiência se temporalize no presente, uma vez que o tempo, nesses termos, só pode ser experienciado na memória - memória que não foi vivida, memória do que não será. Enquanto pessoas não racializadas lembram do que foi e pensam no que será, pessoas racializadas e marcadas pela experiência colonial pensam agora, no presente, num passado que não foi vivido (por conta do potentado colonial) e num futuro que também é impedido pelas coisas que foram projetadas para esse grupo (a necropolítica).

E é aqui que se apresenta como fundamental a atuação do movimento negro. A luta do movimento negro, tanto antes quanto agora, está na construção de uma nova experiência da pessoa negra com a temporalidade, uma experiência para além da dor do passado, para além da colônia para que, assim, possam pensar um futuro de fato, não só de esperança. Essa estrutura temporal - passado colonial, presente resultante da colônia, necropolítica como futuro - torna a atividade política difícil, uma vez que parece um caminho somente de sobrevivência. A atuação do movimento negro quebra essa estrutu- 
ra temporal, uma vez que faz entender que o passado colonial não pode ser lembrado apenas como dor, mas também como espaço de resistência e criação. Aqui, a colônia não pode ser pensada de modo desatrelado dos processos de resistência. Quando esse primeiro ponto da estrutura temporal é repensado, todos os outros precisam ser reinventados.

Construir o passado como colônia/resistência à colônia não é inventar uma nova memória, mas dar um tipo novo de atenção à memória. É contar a história a partir de outro nó na teia de significados da cultura, para além da narrativa dos 'vencedores'. Nesses termos, o presente já não pode mais ser apenas resultado da colônia, mas também dos processos de resistência à colônia. Valorizar a cultura negra em todos os seus aspectos é fundamental e isso está dentro de um prisma de atividade política, atividade de resistência. As utopias nos fazem caminhar, é verdade, mas o que o movimento negro faz está para além de construir utopias: nos mostra, na maneira como redireciona nossa atenção à memória, que o sonho é possível. Se o passado alterou o presente - ainda que não tanto quanto gostaríamos - é no presente que podemos construir novos futuros, assim como aqueles que resistiram no passado construíram esse que nos é um presente.

É isso que o movimento negro educador faz: constrói novos tempos, tempos de liberdade. Construir uma memória de luta, resistência e conquistas é desafiar essa angústia de um passado que não foi vivido. Pensar nas conquistas do passado possibilita esperança num futuro para além das promessas de repetição colonial que são cotidianamente feitas, para além da necropolítica. Revisitar as memórias de um jeito diferente é, para o movimento negro, um compromisso, compromisso esse que cotidianamente possibilita descobertas de negritude positivadas, menos violentas, menos acusativas.

Podemos compreender como essa 'descoberta' muitas vezes se apresenta como etapa para a inserção de pessoas negras em grupos voluntários (Schütz 2012) de negritude e, a partir desse ingresso, 
posicionamentos políticos são tomados. Perceber essas nuances da maneira como se apresentam os racismos cotidianos pode auxiliar no desenvolvimento de alternativas mais direcionadas para que o acontecimento deste evento seja cada vez menos em forma de violência, como ainda muitas vezes tem sido na vida destas pessoas que, por questões históricas, precisam se 'descobrir' negras por mais que o termo 'descoberta' seja a ocorrência surpreendente do que já era esperado (Dastur 2000).

\section{Notas:}

1 Sobre as "categorias intermediárias de cor, como morena, parda e outras" (Petruccelli 2000:31) e seus usos como termos de auto atribuição ou como categorias usadas para a mensuração da população brasileira pelo IBGE, esse autor fez um levantamento da gênese dos termos mais usados para classificar indivíduos resultantes das miscigenações desde o período colonial no Brasil; aponta que, mesmo com diferenças regionais, "pardos, mulatos, mestiços, morenos são as categorias usadas" (Petruccelli 2000:13-15).

2 "Parece, portanto, que o trauma de pessoas negras provém não apenas de eventos de base familiar, como a psicanálise argumenta, mas sim do traumatizante contato com a violenta barbaridade do mundo branco, que é a irracionalidade do racismo que nos coloca sempre como a/o 'Outra/o', como o diferente, como incompatível, como conflitante, como estranha/o e incomum" (Kilomba 2019:40).

3 "A análise fenomenológica toma como certo que existe uma história neurocognitiva a ser contada, mas estuda apenas as estruturas que surgem no nível pessoal, ou seja, estruturas presentes à consciência, introspectivamente disponíveis para o sujeito. A consciência tem muitos elementos, desde experiências sensoriais e sensações corporais, até aspectos não sensoriais, como vontade, emoção, memória e pensamento. A qualquer momento em que estamos despertos estamos conscientes dos padrões de som, luz, cor, som, sensações cinestésicas, humores e emoções internas. Também estamos cientes de como o mundo se apresenta a nós perceptivamente: vemos e ouvimos eventos ocorrendo no espaço ao nosso redor, vemos objetos dispostos e se movendo pelo espaço ao nosso redor, sentimos o movimento de nossos próprios corpos, e experimentamos parte desse movimento como governado por nossa vontade. Nós também temos memórias na forma de imagens recordadas de eventos passados, bem como conhecimento de nossas próprias histórias e um corpo de crenças semanticamente estruturadas que podem ser acessadas mais ou menos quando desejarmos" (Ismael 2010:461; tradução livre).

4 Todos os nomes aqui apresentados são fictícios, conforme acordado com as interlocutoras da pesquisa. 


\section{Referências:}

BRAH, Avtar. 2006. "Diferença, diversidade, diferenciação”. Cadernos Pagu, 26(1):329-376.

CÂMARA, Flávia. 2017. Mulheres negras amazônidas frente à cidade morena: o lugar da psicologia, os territórios de resistência. Dissertação de Mestrado. Belém: UFPA.

COLLINS, Patrícia. 2019. Pensamento Feminista Negro: conhecimento, consciência e a política do empoderamento. São Paulo: Boitempo.

DASTUR, Françoise. 2000. "Waiting and Surprise". Hypatia: Contemporary French Women Philosophers, 15(4):178-189.

FANON, Frantz. 2008. Pele negra, máscaras brancas. Salvador: EDUFBA.

GOMES, Nilma. 2017. O Movimento Negro Educador: saberes construidos nas lutas por emancipação. Rio de Janeiro: Vozes.

ISMAEL, Jenann. 2010. "Temporal Experience”. In ZAHAVI, D. (ed.): The Oxford Handbook of Contemporary Phenomenology, pp. 460-482. Oxford: Oxford University Press.

KILOMBA, Grada. 2019. Memórias da Plantação: episódios de racismo cotidiano. Rio de Janeiro: Cobogó.

MALDONATO, Mauro. 2005. "Arquipélago identidade. O declínio do sujeito autocêntrico e o nascimento do eu múltiplo”. Revista Latinoamericana de Psicopatologia Fundamental, 8(3):480-496.

MBEMBE, Achille. 2018a. Crítica da Razão Negra. São Paulo: n-1 edições.

2018b. Necropolítica: Biopoder, soberania, estado de exceção, política de morte. São Paulo: $n-1$ edições.

NOGUERA, Renato. 2018. "Dos condenados da terra à necropolítica: diálogos entre Frantz Fanon e Achille Mbembe". Revista Latinoamericana do Colégio Internacional de Filosofia, 3:59-73.

PETRUCCELLI, José L. 2000. A Cor denominada: um estudo do suplemento da PME de julho/98. Rio de Janeiro: IBGE/ Departamento de População e Indicadores Sociais.

SCHÜTZ, Alfred. 2012. Sobre Fenomenologia e Relações Sociais. Petrópolis, RJ: Vozes.

SOUZA, Neusa. 1983. Tornar-se negro: as vicissitudes da identidade do negro brasileiro em ascensão social. Rio de Janeiro: Edições Graal.

Abstract: Being black as a political affirmation of a body is not something innate for those who live the experience of being seen as such, but part of an identification process coated with intentionality that aims at a non- 
subordinate existence. Our objective in this article is to understand how the typification of oneself as black, from the event of attributing this identification, establishes a new temporality in the lived experience of black women, implying in different ways of typifying the world of life in the previous temporalities and after the event. We use the ethnographic methodology of phenomenological approach to reach the structures present in the consciousness of black women interlocutors in this research, since consciousness comprises sensory and non-sensory aspects, such as emotion, thought and memory.

Keywords: Identification, Race Relations, Memory, Temporality, Event.

Recebido em outubro de 2020.

Aprovado em março de 2021. 